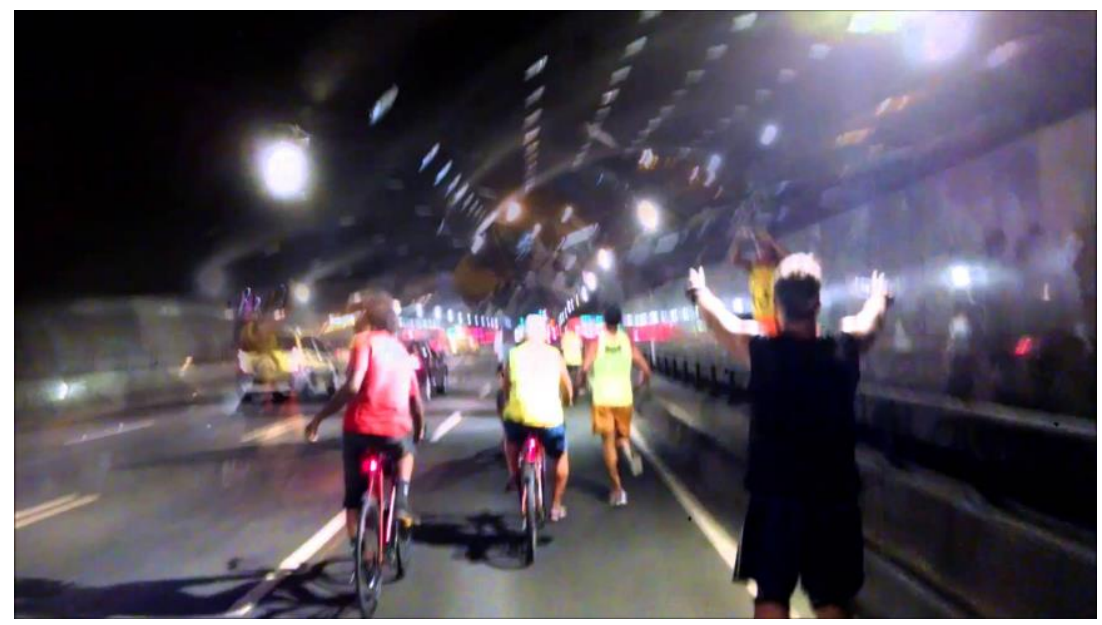

\title{
(Des)igualdade de gênero e a (i)mobilidade urbana contemporânea: uma visão goffmaniana
}

\author{
Gender (des)equality and contemporary urban (im)mobility: a Goffmanian vision
}

Naomi Elizabeth Orton ${ }^{1}$

\begin{abstract}
Resumo
Esse trabalho tem por objetivo examinar as contribuições goffmanianas para o entendimento das interações que se desenvolvem no espaço público e nos movimentos sociais contemporâneos que surgem nele. As questões levantadas advêm de um estudo micro sobre a construção discursiva da horizontalidade por participantes do movimento Massa Crítica. A partir das noções de espaço, tempo e desatenção civil (GOFFMAN, 1963), o artigo busca tecer relações com o contexto macrossocial da via pública metropolitana na atualidade, no qual a investigação se insere. Em seguida, norteado por uma visão construcionista de gênero (GOFFMAN, 1977, 1979), lança-se um olhar crítico sobre práticas naturalizadas não somente no cenário urbano, como também nos próprios movimentos que provocam uma reimaginação de seu uso.
\end{abstract}

Palavras-chave: Movimento social. Gênero. Interação.

\begin{abstract}
This article aims to examine the contributions of Goffman towards understanding of interactions in public, as well as those that take place in contemporary social movements that originate in such space. The issues raised result from a micro study of the discursive construction of horizontality by participants of the movement Critical Mass. Based on the notions of space, time and civil inattention (GOFFMAN, 1963) links are sought between the locus of the investigation and the macro social context of present day urban public space. Finally, guided by a constructionist vision of gender (GOFFMAN, 1977, 1979), the paper takes a critical look at naturalized practices, not only in the urban scenario studied, but also within the very social movements that provoke a reconfiguration of its use.
\end{abstract}

Keywords: Social movements. Gender. Interaction.

\footnotetext{
${ }^{1}$ Doutoranda em Estudos da Linguagem - PPGEL PUC-Rio, e-mail: naomiorton@hotmail.com. Endereço: Rua Marquês de São Vicente, 225 Gávea 22430-060 Rio de Janeiro- RJ.
} 


\section{Introdução: a visão goffmaniana}

Esse artigo representa um recorte de uma investigação mais ampla que toma como seu objeto as práticas discursivas de cicloativistas participantes da "Massa Crítica", Rio de Janeiro, no intuito de refletir sobre a construção da horizontalidade nos movimentos sociais contemporâneos. O presente trabalho examinará as contribuições goffmanianas para o entendimento do movimento social estudado e do contexto macro no qual se insere e problematiza, a (i)mobilidade urbana. Considero as teorizações do autor e "descobridor do infinitamente pequeno ${ }^{2}$ " de suma relevância para a pesquisa uma vez que possibilitam o estudo das interações face-a-face em contextos micro, entendendo que tais interações contribuem para a perpetuação ou desconstrução das forças estruturantes no nível macrossocial. A obra de Goffman pode ser vista como uma ferramenta pela qual é possível analisar e entender o trabalho face-a-face que, de acordo com o autor, produz e reproduz uma ordem, levando ao estabelecimento de rotinas, rituais e instituições que o regulam, embora esta ordem possa também ser questionada. Procuro, assim, identificar essas relações entre os níveis micro e macro, a fim de provocar reflexões sobre práticas naturalizadas na sociedade que possam reforçar e/ou perpetuar determinadas assimetrias. Para tanto, selecionarei aspectos da ordem interacional concebida pelo autor, que considero pertinentes para a investigação proposta, focalizando sua relevância no contexto urbano contemporâneo e mais especificamente, no grupo de ativistas pesquisado.

\section{O contexto urbano contemporâneo e a Massa Crítica}

O movimento cujas práticas interrogarei para os fins desta pesquisa emerge do cenário urbano ao qual venho me referindo, em que atores sociais denunciam a fragmentação, a privatização e a precarização da vida nas cidades que, como aponta o geógrafo George (apud DAMIANI, 2008, p.183), já se transformaram em "universos de concreto, labirintos de vias organizadas que se ligam a anéis rodoviários sobrecarregados de automóveis". Perante esta cena, o habitante dos grandes aglomerados "perdeu a ideia de que poderia participar da posse de sua cidade, ser, de uma maneira ou de outra, responsável pela sua administração e manutenção. Ao contrário, sente-se, às vezes, agredido pelo meio e toma mesmo uma atitude hostil para com ele" (ibid). Esta sensação

\footnotetext{
${ }^{2}$ Bourdieu, P. Goffman, o descobridor do infinitamente pequeno. In: Gastaldo, E (org.). Erving Goffman: desbravador do cotidiano. Porto Alegre: Tomo Editorial, 2004.
} 
de ameaça generalizada, bem como certa impotência face aos deslocamentos pelos grandes centros urbanos, não apenas produz a referida atitude hostil, como é gerada e exacerbada por ela, até que o próprio habitante se sinta deslocado da sua cidade, tornandose seu adversário. A visão evocada, do espaço público como uma matriz estendida de espaço motorizado, podendo apenas ser atravessado, mas não exatamente ocupado, já se tornou realidade em grande número de metrópoles pelo mundo. No mais, tal travessia representa um desafio diário, uma vez que o crescimento vertiginoso das cidades, por mais contraditório que isto pareça, levou à sua paralisação. Assim, instaura-se a (i)mobilidade urbana, uma experiência coletiva, porém vivenciada, pela maior parte das pessoas, isoladamente, nos próprios automóveis que prometeram a almejada liberdade.

Embora a questão da (i)mobilidade urbana apresentada tenha relevância mundial, o foco desse estudo recai sobre ativistas inseridos no cenário brasileiro, no qual políticas públicas de planejamento urbano implementadas ao longo do último século produziram a paisagem atual, de metrópoles rasgadas por infraestruturas centradas em um único meio de transporte: o motorizado, ampliando as distâncias e aumentando a dispersão, a separação e a segregação. A resultante cultura do automóvel - hoje, arraigada na sociedade brasileira, - transformou o carro em um símbolo de status, sendo percebido como a única forma viável de se deslocar por cidades cada vez mais desumanas, a despeito do quadro atual-que coloca em questão as percebidas vantagens desse meio de transporte (LOPES, 2010, p.17).

Diante deste panorama, a bicicleta, bem como outros meios de transporte de propulsão humana, se apresenta como uma alternativa saudável e cidadã. No Brasil, contudo, ela continua sendo sinônimo de "brinquedo de fim de semana" (LUDD, 2005, p.138), perspectiva palpável no Rio de Janeiro pela projetação da infraestrutura cicloviária, a qual apenas contorna as regiões "cartão postal" da cidade, sem atender às necessidades da maioria que se desloca de bicicleta. Embora tal "brinquedo" possa fazer parte do cotidiano, trazendo seu caráter lúdico para os deslocamentos diários, a bicicleta enquanto meio de transporte continua a ser vista como uma escolha de "pessoas não qualificadas" ${ }^{3}$ e sua presença nas vias como um impedimento para uma circulação cada vez maior de automóveis, o que o urbanismo tende a priorizar.

\footnotetext{
${ }^{3}$ É o que afirma o morador de um bairro nobre de São Paulo, Francisco Augusto da Costa Porto em entrevista ao "Estadão" sobre a implantação da ciclovia na rua onde mora. Disponível em: http://saopaulo.estadao.com.br/noticias/geral, moradores-de-areas-nobres-da-capital-acionam-mp-contra-cicloviasde-haddad, 1603212
} 
O direito de a bicicleta transitar pelas rodovias já é garantido pelo $\mathrm{CTB}^{4} \mathrm{e}$ a lei da Mobilidade Urbana ${ }^{5}$ no Brasil prevê a priorização dos meios de transporte não motorizados, bem como o transporte coletivo, a partir da elaboração de Planos de Mobilidade Urbana. Todavia, na prática, o compartilhamento de tais vias nem sempre se dá tão tranquilamente. No Rio, a implantação de um número crescente de estações de bicicletas compartilhadas ${ }^{6}$, além da ampliação da malha cicloviária já se fazem perceptíveis em alguns pontos da cidade, porém a manutenção de ambas, bem como sua adequação à demanda, continuam sendo questões prementes. Ademais, a conscientização dos usuários das rodovias, no que diz respeito à bicicleta enquanto meio de transporte, parece longe do cenário almejado por cicloativistas - que têm como ideal que o respeito mútuo prevaleça e o mais frágil tenha preferência, não apenas de acordo com a lei, mas também nas interações que se desenvolvem nesse espaço.

Diante das questões apresentadas, emergiu o movimento cujo contexto investigo, a Massa Crítica (do inglês “Critical Mass”), a qual provoca uma reconceitualização dos meios de transporte ativos, através de uma intervenção direta no espaço urbano. Caracterizando-se como um movimento efêmero, a Massa Crítica (doravante MC) iniciou-se em São Francisco, em 1992, quando um grupo de ciclistas resolveu pedalar juntos para casa no horário do rush. Segundo o professor norte-americano de comunicação Furness (2007), a "coincidência organizada" (CARLSSON, 1997) se originou em parte como protesto, em parte como celebração, com o objetivo de tomar conta das ruas e demonstrar a força coletiva das pessoas reunidas, além de trazer visibilidade para a bicicleta enquanto meio de transporte. Dessa forma, o movimento propõe que os participantes expressem sua insatisfação com o sistema de transporte vigente e exerçam, nas palavras do filósofo Lefebvre (1991), seu "direito à cidade", embora não estejam vinculados por objetivos ou dogmas predominantes.

Em menos de um ano, a manifestação de caráter alegre chegou a agregar milhares de ciclistas. Paralelamente, houve um efeito multiplicador, fazendo com que diversas MCs se constituíssem ao redor do mundo, auxiliadas parcialmente, pelo advento da Internet, bem como pela ressonância das questões trazidas à tona pela manifestação (BIICKSTEIN \& HANSON, 2001). Chegando ao Brasil em 2002, e ao Rio de Janeiro em

\footnotetext{
${ }^{4}$ Disponível em: http://www.denatran.gov.br/publicacoes/download/ctb.pdf

${ }^{5}$ Versão integral da Lei 12.587/12. Acesso em www.idtpbrasil.org.br em outubro de 2014.

${ }^{6}$ Sistema que disponibiliza bicicletas em diferentes estações e permite que qualquer pessoa retire uma bicicleta em um local e a devolva em outro local, viabilizando, assim, o transporte ponto-a-ponto por tração humana.
} 
2003, o movimento hoje é um fenômeno global, reconhecível pela simples presença de ciclistas congregados na última sexta-feira do mês (LOPES, 2010).

A MC se destaca por sua natureza teoricamente espontânea e horizontal ${ }^{7}$, em princípio sem estatuto ou organização formal, assim como outros movimentos de ação direta$^{8}$. Desse modo, ela visa fomentar um espaço retórico flexível onde os participantes ativamente produzam e disseminem discursos, canalizando a energia e o foco da massa em várias direções, contando sua própria história e assumindo um papel ativo na organização e na promoção do protesto. Nesse sentido, as múltiplas pautas levantadas e as diferentes interpretações trazem um caráter mutável ao movimento, podendo produzir a abertura para "uma verdadeira exploração de significados" (LUDD, 2005, p.125). Tal ideologia se manifesta na noção de "xerocracia" baseada na premissa de que qualquer participante pode produzir e circular, seja durante o protesto ou virtualmente, literatura que versa sobre o pedal ou questões julgadas relacionadas. Inicialmente, em São Francisco, tais textos lidavam com as dificuldades enfrentadas por movimentos sociais contemporâneos em sentido amplo, perpassando questões como a (des)construção de polarizações, e o fomento de uma cultura democrática. Paradoxalmente, os textos eram produzidos, na sua maioria, por um grupo limitado de pessoas, entre elas, Carlsson, que, posteriormente, passou a ser visto como criador do movimento. Embora a noção de xerocracia seja entendida como um dos paradigmas principais do protesto, no momento da elaboração desse trabalho, ela é pouca aproveitada na cidade do Rio de Janeiro, indicando que nem todas as interpretações potenciais são, de fato, exploradas. Na realidade, a descentralização do movimento dificulta a tarefa de apontar seus objetivos com precisão e, por vezes, no contexto investigado, a justaposição de visões divergentes atravessa a linha tênue entre convivência e disputa, tanto pela pauta, quanto pelo discurso.

Tais disputas parecem ter suas origens na natureza do movimento; apesar de se caracterizar como um evento lúdico, e apartidário, a MC, inevitavelmente, exibe objetivos políticos, que vão além do ato de pedalar na via em si. Por vezes, o protesto se pauta em (e se filia a) outras manifestações globais e locais (LOPES, 2010, p.72), como uma no Rio de Janeiro contra a FIFA na véspera da Copa do Mundo de 2014. A decisão de apoiar outras lutas precisa ser votada na concentração do ato, mas, as sugestões aparecem, por

\footnotetext{
${ }^{7}$ De certo modo, a autonomia e o poder de decisão investidos em cada participante, bem como a demarcação dos rumos em conjunto, fazem com que o movimento, no nível micro, se alinhe estruturalmente aos coletivos que surgiram no Brasil a partir das manifestações de junho de 2013, embora no Rio ele atualmente não se defina discursivamente como tal.

${ }^{8}$ Principalmente o Movimento Passe Livre e outros grupos que se preocupam com o direito à cidade.
} 
vezes, no ambiente virtual.

É durante as concentrações, realizadas na Cinelândia, que também costuma ocorrer uma apresentação do movimento e de sua história, destinada aos novos participantes. Dito isto, no Rio, existe pouca rotatividade entre os participantes no que tange ao papel de narrador ${ }^{9}$. Assim, os potenciais significados criados são restringidos, levando à possível construção e/ou reforço de relações assimétricas entre os militantes, ainda que o movimento se proponha como horizontal. Similarmente, o uso de um microfone para se endereçar aos demais, fazer sugestões de trajeto e interagir com outros usuários da via, bem como orientar os participantes de um modo geral, por vezes, acarreta a centralização do movimento, mesmo que o uso do equipamento seja teoricamente aberto a todos os participantes. Posteriormente, nesse trabalho, pretendo refletir mais a fundo sobre tais práticas e a participação efetiva de ativistas diversos nesse meio, explorando eventuais elos com os papéis de gênero socialmente construídos, a partir da visão goffmaniana.

\subsection{Espaço e tempo}

Entre os conceitos goffmanianos que podem ser produtivos para repensar o cenário urbano e seu compartilhamento, destacam-se as noções de espaço e tempo. No que diz respeito ao espaço, em seus estudos, Goffman (1975) delineia uma distinção entre o espaço público, o "palco", e o espaço privado, os "bastidores", em que as interações podem se desenvolver. Essas distinções são relativas, de acordo com o ponto de vista do indivíduo e do contexto, podendo ser tanto respeitadas como violadas, fisicamente ou psicologicamente. Mais especificamente, na sociedade brasileira, Da Matta (2001) observa que o mundo da casa (espaço privado) e o mundo da rua (espaço público) são mais do que meros espaços geográficos, sendo carregados de sentido, marcados por uma relação de oposição e de tensão, ao mesmo tempo em que interagem e se complementam. Para o autor, o espaço privado representa a calma e a tranquilidade, bem como um refúgio do espaço público, que, por sua vez, é reservado ao movimento, ao perigo, à tentação e à luta, assumindo, assim, um caráter tenebroso ${ }^{10}$.

\footnotetext{
${ }^{9}$ No momento de elaboração desse trabalho, na Massa Crítica do Centro do Rio de Janeiro, os militantes que costumam assumir esse papel tendem a ser aqueles do gênero masculino ou que performam traços considerados masculinos, de força e assertividade.

${ }^{10}$ Mais adiante, serão consideradas possíveis relações entre a noção destes dois mundos e os papéis de gênero.
} 
Ao se pensar nas divisões delineadas e sua natureza subjetiva no contexto urbano volta-se a atenção as tendências dominantes na distribuição espacial de atividades urbanas ao longo das últimas décadas. Isso tem focalizado o uso rotineiro e irrestrito dos veículos motorizados por meio do zoneamento urbano" ${ }^{11}$, entre outras políticas (CONTROL, 2005, p.109). Tais tendências têm alimentado um consenso compartilhado de que esses espaços públicos são destinados para o uso quase exclusivo dos motorizados (Ludd, 2005:126). Essa crença se faz perceptível nas lutas pelo território ocorridas durante os deslocamentos, e na normalização do "direito" a estacionar o veículo particular em um espaço denominado público, seja na via, seja em cima da calçada. Assim, o usuário dos modais ativos ou o pedestre que procura exercer seu direito à via pública, é percebido como intruso, podendo ser hostilizado ou agredido pelo simples fato de escolher se deslocar de outra forma que não o motorizado. Como identifica o filósofo Gorz (2005, p.74), a agressividade gerada pelo planejamento urbano contemporâneo, por vezes, leva o motorista a "assassina (r) simbolicamente 'os outros', que aparecem para ele meramente como obstáculos materiais à sua própria velocidade". Nesse sentido, testemunhamos uma espécie de inconsciência social, uma vez que os interesses particulares se sobrepõem ao interesse comum.

No Brasil, no caso dos modais ativos e, mais especificamente, da bicicleta, o CTB determina que, na ausência de ciclovia, ciclofaixa ou acostamento transitável, a preferência é do ciclista, e que os veículos automotores devem reduzir a velocidade de forma compatível com a segurança no trânsito para ultrapassá-lo, além de guardar distância lateral de um metro e meio durante a ultrapassagem (LUDD, 2005, p.127). Porém, em uma via em que diferentes modais precisam compartilhar esse espaço, a "competição" (DA MATTA, 2001), que caracteriza o comportamento nesse meio, encontra-se atravessada por relações desiguais. Como consequência, alguns motoristas por vezes se apropriam da força para intimidar os menores e inverter os valores previstos pela lei ${ }^{12}$, os quais, por vezes, permanecem apenas no plano teórico.

Na realidade, na cidade do Rio de Janeiro, assim como em outras cidades, as próprias políticas públicas implementadas, poucas vezes, traduzem o que está codificado na lei, priorizando o fluxo dos automóveis em vez dos pedestres e dos não motorizados.

\footnotetext{
${ }^{11} \mathrm{O}$ regulamento do uso do solo urbano, destinando o ao uso exclusivamente comercial ou residencial por meio da aplicação de um sistema legislativo tem aumentado as distâncias a serem percorridas dos deslocamentos diários, criando, simultaneamente, a necessidade de construir mais rodovias.

${ }^{12} \mathrm{http}: / /$ www.ctbdigital.com.br/?p=Comentarios\&Registro $=52 \&$ campo_busca $=\&$ artigo $=68$; http://www.ctbdigital.com.br/?p=Comentarios\&Registro $=51 \&$ campo_busca $=\&$ artigo $=29$
} 
Por meio dessas medidas, concretiza-se a percepção generalizada de que o espaço público pertence, antes de tudo, aos veículos motorizados, resultando em uma privatização psicológica ${ }^{13}$ do espaço. A obrigação dos pedestres a usarem passarelas ou passagens subterrâneas, para que não "interfiram" no fluxo dos automóveis, não somente dificulta seu deslocamento, como pode colocar sua segurança em risco, os forçando a passar por espaços muitas vezes desertos. No mais, a observação das faixas de pedestres existentes no Rio de Janeiro e o tempo permitido para fazer a travessia, nos sugere uma hierarquia contrária àquela prevista pela lei, uma vez que a travessia de avenidas largas, muitas vezes, precisa ser feita em duas etapas. Como questiona o ativista Control (2005, p.106), "havia uma época em que tínhamos (nós, os pedestres) o direito de passar". Todavia, temos naturalizado a precedência, premência e preferência do automóvel, mesmo que tal coisa não seja sancionada pela lei.

Esse quadro é ainda agravado pelos poucos projetos de construção de infraestrutura cicloviária, os quais recorrentemente implicam a redução do espaço pedestre ao invés daquele destinado aos automóveis, acarretando o compartilhamento de calçadas que já não possuem espaço suficiente para o deslocamento a pé. A segregação do espaço dessa forma parece contribuir para o pensamento disseminado de que os pedestres e os usuários dos modais ativos podem apenas circular onde existe sinalização para tal, ainda que essas infraestruturas possam ser inadequadas ou até inexistentes em determinados trechos.

Paradoxalmente, apesar desses usuários serem recorrentemente excluídos do espaço público, o motorista ainda não consegue obter nenhuma satisfação dele, uma vez que "não realmente usa o espaço que cruza (...) (t)udo que faz é tentar minimizá-lo, passando por ele o mais rapidamente possível" (CONTROL, 2005, p.109). Ou seja, a eliminação dos demais incentiva o aumento da velocidade, realimentando a visão de que o espaço "público" representa esse território "particular" dos motoristas, ao mesmo tempo em que produz a realidade que vivemos atualmente: a de cidades desumanas. Como consequência, emerge a concepção de que os outros usuários da via estão, de fato, violando o espaço particular do motorista. Perante tal entendimento, a reivindicação do espaço, ao adotar o uso de um modal ativo, é visto por alguns como um ato não somente político, como também transgressivo, "necessitando" do uso da força e da agressão para que o "transgressor" seja expulso ${ }^{14}$.

\footnotetext{
${ }^{13}$ Uma vez que o espaço continua público de acordo com a lei.

${ }^{14}$ Ponto ao qual gostaria de retornar posteriormente ao debater a questão de gênero nesse cenário.
} 
Parece, portanto, que a perspectiva de que o espaço público pertence aos automóveis advém parcialmente da crença de que eles também garantem um deslocamento mais veloz. Como critica Gorz (2005, p.73), o carro particular representa um bem de luxo que é: "somente desejável e vantajoso a partir do momento em que a massa não dispõe de um". Tal luxo não pode ser democratizado uma vez que, quando todos ascendem ao luxo, ninguém tira mais proveito dele. Na verdade, sua massificação já fez com que ele não ofereça mais o privilégio de circular muito mais rapidamente que os demais. Posto isso, sua desvalorização prática ainda não acarretou sua desvalorização ideológica: o mito do prazer e do benefício do carro persiste. De acordo com o autor, essa convicção ilusória nas vantagens do automóvel, principalmente no que tange à sua velocidade, continua porque o carro: "golpeou os transportes coletivos, alterou o urbanismo e o hábitat e transferiu ao carro certas funções que sua própria difusão tornou necessárias" (IBID, p.75). Sendo assim, muitos ainda almejam alcançar o "privilégio" do carro particular, ainda que, contraditoriamente, ele não represente mais tal coisa, já que sua abundância criou uma paralisação geral.

Essas considerações sobre a velocidade do tráfego nos levam a contemplar a segunda noção goffmaniana mencionada no início dessa subseção, a de tempo. O sociólogo Castells (1999) postula que, na contemporaneidade, nossa noção de tempo tem mudado graças aos eficazes meios de comunicação, os quais possibilitam que a sociedade experimente uma nova percepção mais rápida do tempo e da realidade. Como resultado, a expectativa do tempo de que devamos passar no trânsito se afasta cada vez mais da realidade que vivenciamos, podendo levar a frustração ou até produzir posturas agressivas (GUIMARÃES, 2008).

No contexto das interações, Goffman (1963) observa que o tempo está intimamente relacionado à informação, uma vez que quanto mais tempo a interação leva, mais informação pode ser trocada. No entanto, no trânsito, o objetivo de muitos, de chegar o mais rápido possível ao destino, dificulta essa troca de informações. Os automóveis prometem reduzir o tempo de deslocamento e podem atingir velocidades acima dos não motorizados, ainda que nos grandes centros urbanos sua velocidade média continue bem abaixo dos modais ativos ${ }^{15}$. Apesar dessa lentidão, as possibilidades de interação entre o motorista e os demais são poucas, uma vez que o veículo em si já encarcere o motorista, o mantendo no espaço "particular" do seu veículo em vez dele participar plenamente do

\footnotetext{
${ }^{15}$ http://www.detran.rs.gov.br/conteudo/42198/bicicleta-chega-mais-rapido-no-desafio-intermodal-dodetran-rs
} 
ambiente em que está inserido. Como temos observado, o código de trânsito construído na rua pelas práticas dos diferentes usuários privilegia o motorista, uma vez que os demais se encontram em posições subordinadas, dificultando a negociação de um terreno mais igualitário. As normas estabelecidas nessas interações urbanas são então reforçadas por buzinas ou gritos de: "saia da rua!", lançados de dentro de veículos, muitas vezes enquanto passam em alta velocidade, não visando algum tipo de diálogo.

$\mathrm{Na}$ realidade, o motorista passou a ter medo de deixar sua cela, considerando-a uma protetora em vez de opressora, evitando assim, a interação com o outro (CONTROL, 2005, p.105). Já a utilização de deslocamento ao ar livre, como caminhada ou bicicleta, proporciona exposição às áreas verdes e encontros com outras pessoas, uma vez que o usuário está imerso em seu ambiente. A possibilidade de parar ou estacionar como muito mais facilidade, fomenta as interações e contribui para a construção do senso de comunidade do cidadão. Como observa o sociólogo Ludd (2005, p.126):

Se a viabilidade de locomoção rotineira por bicicleta fosse um imperativo no desenvolvimento e planejamento das cidades, isso significaria, provavelmente, cidades em uma escala mais humana, implicaria descentralização e condições mais propícias para um espírito e relacionamento comunitários.

O uso do automóvel, por sua vez, produz uma paisagem distinta, em que o outro se torna inimigo. O veículo em si cria uma barreira entre o indivíduo e seu ambiente, fomentando a condição de anonimato que, tal como em um ambiente virtual (JENKINS, 2010, p.264) possibilita que o indivíduo se envolva em conduta pela qual sabe que mais dificilmente terá que responder. Tal modal reduz a possibilidade de trocar informações e, como consequência, a possibilidade de reflexões ou algum entendimento mútuo entre os diferentes usuários da via. Goffman (1975) afirma que quanto mais informações são trocadas, mais difícil se torna o gerenciamento de informações, isto é, a arte de impressionar os outros com a imagem desejada de si. Nesse sentido, a oportunidade de diálogo no trânsito poderia contribuir para a problematização do percebido status do motorista como o único usuário legítimo do espaço, provocando questionamentos a partir de um entendimento mais aprofundado das intenções e dos direitos dos outros usuários da via. 


\section{O gerenciamento do trânsito}

O espaço urbano que adentro neste trabalho pode ser considerado um dos espaços mais significativos em que as "relações em público" se desenvolvem. Em seus estudos Goffman (1963) delineou uma analogia entre o movimento dos pedestres pelo meio urbano e o trânsito da via, entendendo que, como qualquer outro tipo de trânsito, o deslocamento à pé depende de regras explícitas e implícitas para evitar a colisão e o conflito, bem como rotinas que contam como deslocamento competente ${ }^{16}$. Assim como o sociólogo Jenkins (2010, p.266), considero o "trânsito" uma das principais metáforas analíticas de Goffman, resumindo e comunicando a observação e a improvisação de regras no meio urbano. Representa também, um ponto de partida produtivo para refletir sobre as interações nos centros urbanos contemporâneos, sejam interações entre pedestres ou entre modais com status diferenciado. Busco, assim, explorar possíveis consequências das novas tecnologias para a noção de "desatenção civil17", dentre outras, além de considerar o potencial de novas iniciativas para humanizar esse trânsito por meio de uma negociação mais igualitária do espaço.

\subsection{Desatenção civil e o "podestre"}

O deslocamento a pé, principalmente em ruas movimentadas, necessita do que Goffman (1963) chamou de "desatenção civil", a noção de que os atores sociais reconhecem tacitamente a presença do outro, mutuamente respeitando esse outro em um processo constante de negociação espacial. Trata-se de trabalho de face passageiro em que indivíduos emitem e interpretem pistas visuais e sonoras em relação às suas intenções e às do outro, para que o "trânsito" flua, adaptando sua navegação a fim de respeitar a passagem desse outro.

De acordo com Jenkins (2010), na contemporaneidade esse cenário tem mudado devido às novas tecnologias de comunicação, que fazem com que o pedestre seja menos atento. Denominando o pedestre que usa aparelhos eletrônicos com fone de ouvido na rua de "podestre1" ${ }^{18}$, Jenkins postula que tal prática prejudica potencialmente a negociação espacial, uma vez que cria uma bolha, insulando o pedestre da ação. Assim, ele será menos adepto a interpretar as pistas necessárias para fazer um trajeto competente, podendo

16 Rotinas socialmente estabelecidas para evitar a colisão com o outro.

17 Goffman, 1963.

${ }^{18}$ Da palavra "ipod", aparelho para ouvir música da marca Apple. 
provocar colisões interpessoais, sejam esses esbarros insignificantes ou não.

No entanto, diferente do motorista, o pedestre e o usuário dos modais ativos estão imersos em seu meio ambiente. Dessa forma, ainda que adotem o uso desses aparelhos, interagem com o mundo ao redor, podendo ainda fazer uso de outras pistas. Já o motorista que faz uso das tecnologias de comunicação, como telefones de celular, se rodeia de aço, se blindando de seu exterior e dos outros. Ademais, esse mesmo aço que separa o motorista de seu ambiente representa um outro agravante, visto que pode produzir consequências consideravelmente mais graves, caso não mantenha a atenção necessária para a negociação competente do espaço (GRANIER, 2005, p.119).

Desse modo, o conceito do podestre (Jenkins, 2010) parece compactuar com a culpabilização da vítima no trânsito. Em vez de os motoristas se responsabilizarem pela segurança dos mais frágeis, como previsto pela lei, o termo sugere que a segurança é uma obrigação individual, percepção tangível também no grito de "quer morrer?!", frequentemente direcionado a ciclistas que reivindicam seu espaço nas ruas (GRANIER, 2005, p.104). Tais discursos reforçam a percepção de que é perigoso pedalar na via e de que quem faz essa escolha, assume o risco.

No contexto desse estudo, tal mensagem é veiculada também pela intervenção do Estado nesse espaço - perceptível nos poucos projetos de infraestrutura cicloviária, por meio de avisos de "parar" ao se aproximar de um retorno, ainda que a preferência seja do menor. Os próprios agentes do Estado, engajados em facilitar o fluxo do trânsito, transferem a mesma responsabilidade ao menor, por vezes recomendando que o ciclista pedale pela calçada em vez de transitar pela via, no interesse de sua própria segurança. No mais, veículos que representam o Estado, como viaturas e até ambulâncias, deixam de dar a devida distância na ultrapassagem, criando a impressão de que, na empreitada de salvar vidas, outras se tornam descartáveis.

\subsection{Vias compartilhadas}

Com o crescimento dos centros urbanos na contemporaneidade e o aumento consequente de todos os tipos de trânsito, Jenkins (2010) afirma que sistemas de gerenciamento de trânsito têm se tornado cada vez mais complexos e invasivos. O autor argumenta que a demarcação espacial, pelo qual compreende-se: superfícies diferentes; marcações rodoviárias; rotatórias; lombadas; placas; semáforos e radares, constitui uma espécie de sistema de gerenciamento de trânsito tecnológico, comunicando aos usuários 
o que precisam fazer e comunicando àqueles que gerenciam o trânsito o que está em andamento. Assim, a autonomia e o poder de decisão observados por Goffman (1963), são gradualmente retirados dos usuários, que se tornam sujeitos ao sistema tecnológico.

Perante esse novo cenário, acho fundamental questionar se a imposição de regras advindas do Estado pode, de fato, garantir um gerenciamento do trânsito mais bemsucedido do que a negociação espacial identificada por Goffman (1963), principalmente no que diz respeito a eventuais colisões. Na cidade do Rio de Janeiro, é possível observar que a mobilização de agentes de trânsito em cruzamentos críticos não impede que esses sejam fechados por veículos como ônibus nos horários de pique. Em um estudo realizado na zona sul da mesma cidade, a socióloga Guimarães (2008) percebe a dificuldade de eliminar o elemento de improvisação no que diz respeito às regras de trânsito. De acordo com a pesquisadora, o medo da violência na cidade do Rio de Janeiro faz com que o instinto de sobrevivência prevaleça, levando motoristas a enxergarem esses aparatos normatizadores, como a sinalização semafórica, como simples obstáculos a serem ultrapassados, principalmente durante determinados horários do dia. Desta maneira, nasce um padrão de comportamento do próprio usuário, a despeito do que é oficialmente decretado pelo Estado.

Além disso, como já observamos, os sistemas tecnológicos atuais, muitas vezes, comunicam uma mensagem contrária àquela prevista pela lei, compactuando com a crença de que a preferência é, de fato, dos maiores. No mais, percebe-se que a negociação de regras sociais no que diz respeito ao compartilhamento da via torna-se mais complexa quando se dá entre os motorizados e os não motorizados, uma vez que o poder não é distribuído igualmente nessas interações.

Jenkins (2010) ainda postula sobre uma realidade alternativa, de espaço compartilhado, uma abordagem desenvolvida na Holanda que tem sido cada vez mais difundida. Essa proposta implica a redução da segregação do espaço, com distinções mais nebulosas entre o espaço pedestre, veículo não motorizado e motorizado. Além disso, o gerenciamento do trânsito é devolvido ao usuário, com menos interferência do Estado por meio de sistemas tecnológicos. Como resultado, os usuários são obrigados a interagir um com o outro para negociar sua passagem pelo espaço. Posto isso, para que seja construído um espaço mais humano e mais igualitário, acho imprescindível levar em consideração o fato de que os diferentes usuários da via ocupam diferentes lugares no exercício do poder, os posicionando "de forma diferenciada nas assimetrias/simetrias interacionais" (MOITA LOPES, 2001, p.60). Nesse sentido, o motorista pode se impor por meio da força, 
perpetuando as hierarquias em relação ao uso do espaço. Para que o conceito não permaneça apenas no plano utópico, talvez seja necessário introduzir medidas que favoreçam os usuários mais frágeis, para que estes possam se empoderar e tornar essa concepção uma realidade.

\subsubsection{Intervenção urbana e a violência simbólica}

A partir de alguns exemplos de intervenção urbana a seguir, propõe-se, portanto, uma reflexão sobre a possibilidade de produzir um cenário mais humano no contexto específico estudado. Por meio dos casos aqui apresentados, busca-se entender as relações de poder estabelecidas não somente entre os diferentes usuários da via, como também entre os usuários e o Estado:-quando estes reivindicam seu poder de tomada de decisão com vistas a reduzir o vão entre o compartilhamento da via previsto pela lei, e a subordinação dos mais fracos na prática.

O bairro em que moro é estritamente residencial e não há passagem de trânsito devido a sua localização geográfica. O limite de velocidade varia entre 30 e $40 \mathrm{~km} / \mathrm{h}$ e existem lombadas em algumas das vias. Posto isso, não há nenhuma faixa de pedestres em todo o bairro, dificultando a travessia e contribuindo, na minha opinião, para a visão de que o espaço é reservado aos automóveis.

A rua onde resido é estreita e, de um lado, existem vagas de estacionamento. Do outro lado, é comum a permanência de veículos estacionados em cima da calçada, também já estreita. $\mathrm{O}$ asfalto da rua conta com diversos buracos e alaga com facilidade, dificultando a passagem por bicicleta. Por conta de sua largura, torna-se também difícil o veículo motorizado fazer uma ultrapassagem segura de um modal ativo, precisando, assim, esperar até o final dela, sendo que ela conta com uma extensão de menos de quinhentos metros ao total. No entanto, ao pedalar defensivamente, ocupando a faixa, é comum ser hostilizado por motoristas, através de buzinas, ameaças verbais e tentativas de forçar a ultrapassagem. Com isso em mente, instalei uma placa produzida em uma oficina de intervenção urbana que exibia o pedido "compartilhe a via" com a imagem de uma bicicleta e um carro. Algum tempo depois, apareceu escrita em cima da placa a mensagem "use a ciclovia", embora esta rua não conte com infraestrutura cicloviária alguma. Tal mensagem parecia comunicar a visão de que onde não existe infraestrutura cicloviária, o uso da bicicleta seria proibido, uma crença possivelmente reforçada pela segregação da via para o uso dos modais ativos em outros locais. Após uma reflexão, 
resolvi tentar estabelecer um diálogo com o autor da mensagem, mesmo que fosse por escrito. Assim, abaixo da mensagem acrescentei o convite "vamos construir uma?". No entanto, pouco tempo depois encontrei a placa quebrada, arrancada do poste onde tinha instalado. Essa ação parecia representar uma violência simbólica. Do mesmo modo que observamos no trânsito, o interlocutor respondeu com força e agressividade, ao invés de se mostrar aberto ao diálogo. Nesse sentido, a impessoalização de uma placa, tal como qualquer outra máquina que pretende regular o trânsito não parece fomentar a possibilidade de negociação entre os usuários, possivelmente contribuindo para a desumanização da cidade.

Na cidade vizinha, chamada Niterói, é possível também observar tentativas por parte dos cidadãos a reivindicar seu poder de decisão no que diz respeito ao gerenciamento do trânsito. A pintura de uma travessia de pedestres por um grupo de moradores, ocorrida em 2015, devolveu ao pedestre seu direito de fazer a travessia com prioridade em uma área onde apenas existia uma faixa inacabada. A intervenção colocou na prática a mensagem publicitária da prefeitura de que "a prioridade é do pedestre", pouco visível na cidade até então. No entanto, após a publicação de uma matéria no jornal local sobre a ação dos moradores, a faixa foi apagada pela mesma prefeitura. Dessa forma, entendemos que, apesar de os moradores terem autonomia para tomar decisões em relação ao uso do espaço, o Estado, da mesma forma que o motorista, pode responder com força ao invés de diálogo, passando uma mensagem distinta daquela contida na sua própria publicidade ou no CTB.

Todavia, a prefeitura também pode agir para produzir uma cidade mais humana, efeito perceptível na cidade de São Paulo após a redução da velocidade nas marginais da cidade em 2015. Tal ação limitou as velocidades a $50 \mathrm{~km} / \mathrm{h}, 60 \mathrm{~km} / \mathrm{h}$ e $70 \mathrm{~km} / \mathrm{h}$ nas pistas locais, centrais e expressas, onde antigamente os limites eram de 90, 70 e 70, respectivamente. Sua implementação gerou revolta entre alguns motoristas, embora estudos sugerissem que em horários de pique a velocidade média variava entre $12 \mathrm{~km} / \mathrm{h}$ a $20 \mathrm{~km} / \mathrm{h}$ no sentido centro-bairro. ${ }^{19}$ Após um ano, estudos indicaram que a quantidade de acidentes com vítimas e a lentidão nas vias apresentaram queda de 38,5\% e $8,7 \% \cdot{ }^{20}$ Assim, parece que, em determinados casos, a intervenção do Estado pode auxiliar

\footnotetext{
${ }^{19} \mathrm{http}$ :/exame.abril.com.br/brasil/reduzir-a-velocidade-das-marginais-em-sp-e-mesmo-tao-ruim/

${ }^{20} \mathrm{http}$ //ultimosegundo.ig.com.br/igvigilante/transito/2016-07-20/reducao-da-velocidade-nasmarginais.html
} 
o fluxo de trânsito e a evitação de colisões, pelo menos no caso dos veículos motorizados ${ }^{21}$. Posto isso, tais intervenções produzem um efeito efêmero, uma vez que parecem apenas alterar a conduta do usuário sob ameaça de multa. Em 2017, a nova gestão da prefeitura tem procurado estabelecer mudanças nas velocidades e as colisões nos primeiros trinta dias dessa mudança já superaram a média mensal de $2016^{22}$.

Entendemos, portanto, que a intervenção do Estado, assim como a intervenção cidadã, talvez não seja suficiente para produzir uma mudança duradoura no comportamento dos usuários. Assim sendo, torna-se necessário pensar em medidas que possam desafiar crenças enraizadas subjacentes às rotinas e aos rituais reguladores das interações entre diferentes usuários nas cidades contemporâneas, entendendo que estes encontram-se atravessadas por relações de poder desiguais.

\section{O Arranjo entre os sexos}

Quando se pensa na desigualdade entre os diferentes usuários da via pública e no uso de força e agressividade para reforçar essas hierarquias, a atenção inevitavelmente recai sobre a questão de gênero. Goffman (1977, p.301-3) concebe o gênero como social construído, afirmando que aprendemos a performar determinados papéis na sociedade de acordo com o pertencimento às categorias de sexo culturalmente estabelecidas. Essas categorias normativas prescrevem o modo como vivenciamos o mundo, nos tornando sujeitos a expectativas sociais diferentes, ao mesmo tempo em que fornecem uma base para desculpar, justificar, explicar ou condenar a conduta do indivíduo. Assim, as percebidas diferenças entre os sexos são produzidas pela ritualização dos papéis de gênero e pela segregação institucional, ao invés de serem inatas ou decorrentes de diferenças biológicas.

As condutas estereotipadas aprendidas e convencionalizadas na socialização são denominadas por Goffman (1979) como "displays" de gênero. Seu significado não está no comportamento em si, "mas sim nos códigos culturais que (nele imprime) significado" (Gastaldo (2008, p.152). Ao escolher performar determinados displays, o indivíduo comunica tacitamente aos outros o seu alinhamento a uma determinada situação e aos rituais de interação esperados nele. Desse modo, a natureza do gênero reside na

\footnotetext{
${ }^{21}$ Em 2017 a nova gestão da prefeitura tem procurado estabelecer mudanças nas velocidades e já ocorreu uma colisão no primeiro dia dessa mudança, em 25 de janeiro de 2017.

$22 \mathrm{http}$ ://www1.folha.uol.com.br/cotidiano/2017/03/1865220-apos-novos-limites-acidentes-nas-marginaissuperam-media-de-2016.shtml
} 
capacidade e na vontade para aprender a fornecer e seguir prescrições de masculinidade e feminilidade em um processo que legitima e realimenta a crença na sua base biológica (GOFFMAN, 1979, p.8).

Goffman (1979:5) observa que a hiper-ritualização dos displays, em anúncios de publicidade, por exemplo, sustentam uma relação de poder naturalizada, apresentando a subordinação da mulher como uma obviedade, quando, na realidade, imagens como estas fundamentam, reiteram e sustentam essa relação. Assim, perpetua-se uma hegemonia, deixando de problematizar uma profunda desigualdade de gênero (GASTALDO, 2008; SMITH, 2010). Tal dominância normalizada do homem é igualmente perceptível no gerenciamento da interação face a face. Quem inicia a fala, a quem a fala é endereçada, quem se auto seleciona na tomada de turnos, quem estabelece e muda de assunto, a quem é dado atenção e peso quando fala e assim por diante, são todos papéis aprendidos socialmente. Dessa forma, a mulher que assume um papel mais ativo nas interações, como por exemplo, no contexto dos movimentos sociais, arrisca ser taxada de "autoritária", dada a passividade esperada daquelas consideradas da categoria de sexo feminino (GOFFMAN, 1977, p.324).

Assim sendo, pedalar na via parece uma forma de desafiar os papéis de gênero, já que à mulher cabe as características sensíveis e delicadas, apropriadas ao espaço privado ou doméstico (DA MATTA, 2000). Ao adotar o uso de um modal ativo para se deslocar, além de questionar o uso do espaço, ela coloca em xeque o comportamento esperado de seu gênero, constituindo, portanto, uma dupla contestação. Como consequência, ela pode sofrer uma dupla repressão por aqueles que desejam manter os paradigmas atuais. Ao mostrar liberdade, autonomia e empoderamento, ela pode ficar sujeita a assédio, bem como sofrer sanções sociais que vão além das agressões verbais ou físicas direcionadas a todos que reivindicam seu espaço na via pública. No mais, a carga de responsabilidade pela própria segurança torna-se dobrada, uma vez que ela é culpada tanto enquanto ciclista, como enquanto mulher. Tal culpa é, mais uma vez, corroborada pelo Estado: um exemplo disso é o próprio site da Delegacia da Mulher que aconselhe que a mulher não caminhe sozinha por ruas mal iluminadas ${ }^{23}$, a fim de combater a violência de gênero.

\footnotetext{
${ }^{23} \mathrm{http}: / /$ www.policiacivil.pr.gov.br/modules/conteudo/conteudo.php?conteudo=9
} 


\subsection{Gênero e o compartilhamento da via}

Em alusão a Beauvoir²4, o escritor Ducharme (1967, apud GRANIER, 2005, p.119) afirma que "não se pode nascer automóvel; torna-se automóvel, de repente". Nesse sentido, o condutor do automóvel forma um corpo com seu automóvel, se tornando automóvel em si. O carro é concebido como um instrumento de poder e destruição que, além de matar o ser humano, faz com que o condutor perca seus traços humanos, tornando-se bruto, uma vez que o veículo: "o(s) deforma, o(s) desfigura, o(s) nega -- uma pessoa ao volante não é mais um ser humano" (Granier, ibid). A naturalização dessa transformação do humano em máquina é palpável na grande mídia quando noticia, por exemplo, que "carro mata seis ${ }^{25}$ ". Notícias essas, que, quase sem exceção, tornam o veículo o sujeito ativo da frase, isentando o motorista de qualquer responsabilidade por suas ações.

No mais, a referência feita a Beauvoir por Ducharme, impreterivelmente, provoca reflexões no que tange às performances de gênero e ao comportamento do condutor no trânsito. Na sociedade ocidental, a sexualidade masculina tem sido construída como mecânica e agressiva e o carro veio a representar esse poder masculino. Como afirma Control (2005, p.110): "como motorista, você tem poder sobre os pedestres, sobre os passageiros e sobre o espaço urbano. Assim, o carro representa a própria realidade dele: o poder motorizado".

Tal poder também se faz presente nos anúncios publicitários de automóveis, cuja relação com a construção social de gênero Goffman (1979) explorou. Anúncios desse tipo tendem a ser voltados especificamente para o gênero masculino, prometendo, além de poder, dominância e liberdade (GORZ, 2005, p.76). A linguista Magalhães (2005) observa que tais anúncios criam associações entre a performance do corpo da mulher e a performance do automóvel. Parece, portanto, que o motorista procura dominar o carro e as ruas do mesmo modo que o homem procura dominar a mulher. Paradoxalmente, o carro cria dependência em vez de proporcionar liberdade, visto que a sua manutenção e o combustível necessário para se locomover têm custo elevado, diferente, por exemplo, dos modais ativos (GORZ, 2005, p.76).

\footnotetext{
${ }^{24}$ Se refere à frase cunhada por Beauvoir "não se nasce mulher, torna-se mulher" em sua obra "O segundo sexo", considerada uma das obras feministas primordiais.

${ }^{25} \mathrm{http}$ //www.correio24horas.com.br/detalhe/salvador/noticia/caminhao-atropela-carro-bate-em-onibus-edeixa-ao-menos-quatro-feridos-na-jaqueira-do-carneiro/?cHash=f00a297d0d083d67460fcb3e308afef9 http://g1.globo.com/bahia/noticia/2016/12/guard-rail-atravessa-carro-e-pai-morre-ao-voltar-de-formaturada-filha-na-ba.html
} 
No trânsito, o motorista se encontra isolado e ao mesmo tempo, incorporado a um grande esquema de dominação: o do capitalismo; da fabricação de automóveis até a indústria do petróleo das quais ele depende. Ele se torna vítima de um sistema de tráfego que somente pode existir em um estado de expansão perpétua, aumentando as distâncias através das quais as pessoas devem ser transportadas, e depois, engenhosamente, oferecendo uma solução a esse problema: o carro (CONTROL, 2005, p.110-1).

Já o usuário dos modais ativos, assim como o ciclista, "invadem" o espaço em que foi prometida a possibilidade de uma performance especificamente masculina e de dominância. Desse modo, quando o ciclista, com todo seu livre-arbítrio, passa, por exemplo, pelo corredor, sua liberdade aparenta ser um grande incômodo para o motorista preso no trânsito, principalmente, quando se manifesta no corpo de mulher, palpável nos gritos de abuso e agressão advindos daqueles que encontram-se paralisados. Conforme já observado, a inversão dos papéis e dos displays esperados gera revolta, nos mostrando a resistência de alguns membros da sociedade à construção de espaços mais igualitários.

\subsection{Gênero e os movimentos sociais contemporâneos}

No que diz respeito aos papéis de gênero no movimento social que adentro na presente pesquisa, a MC em si é concebida pelo geógrafo Bruzzone (2012) como uma performance de gênero, argumentando que ela também performa o gênero masculino, excluindo quem se distancia desse gênero na sua performance. Tal performance é perceptível nos processos de tomada de decisões, sendo que o percurso escolhido costuma seguir a sugestão de quem fala mais alto ou é visto como um líder mais 'natural'. Por isso, a fim de encontrar voz nesse meio, as mulheres têm precisado performar traços masculinos em suas interações e por isso, podem ser taxadas de "agressivas", e assim, deslegitimadas como participantes do espaço. Essa desqualificação do outro ecoa o tratamento do ciclista que reage diante das agressões sofridas durante seus deslocamentos, muitas vezes percebido também como "agressivo". Nesse sentido, da mesma maneira que o ciclista pode ser lembrado de seu lugar na escala hierárquica da via por meio de uma buzina, independente de quem comete a infração, a mulher também pode ser silenciada dentro do próprio movimento que se propõe a combater tal quadro.

Dessa forma, a MC perpetua um machismo sutil, em que as desigualdades de gênero são reforçadas pelas práticas discursivas e sociais dos participantes. Posto isso, 
mesmo que a identidade da massa crítica seja entendida como masculina, por ser construída pelos participantes, ela também pode ser reconstruída em outras bases. De acordo com Bruzzone (2012), as performances de gênero se baseiam em objetivos. Os objetivos da MC não são definidos, mas é possível entender que ela visa provocar mudanças sociais, embora não faça demandas específicas ao Estado, por exemplo. Ela se direciona a práticas culturais que são instanciadas por políticas e medidas do Estado, mas não somente. Ela se opõe a uma cultura enraizada, a da "carrocracia" e, apesar de não poder exigir nada dessa cultura, pode desafiá-la, da mesma forma que ela pode desafiar o sistema patriarcal.

Ao dizer que os movimentos sociais contemporâneos são horizontais sem questionamentos, pressupomos que elas sejam livres de lideranças e assim, livres de regimes de poder. Fraser (1997, p.74, 77-9) afirma que o potencial utópico de espaços livres de status e desigualdades até hoje não se concretizou. De acordo com a autora, não é possível simplesmente eliminar as desigualdades e estabelecer um espaço "neutro", uma vez que as pessoas ainda estão inseridas em sociedades em que existem relações estruturais de dominância e subordinação. Ao considerar que essas assimetrias simplesmente não existem, cria-se uma falsa democracia que não fomenta a participação de minorias, assim como observamos no caso do compartilhamento da via. Embora possam estar oficialmente presentes, aqueles com status inferior continuam a ser marginalizados, constituindo, assim, uma perpetuação das desigualdades que os movimentos sociais justamente objetivam contestar. É possível entender, portanto, que quando a exclusão não é formal ou explícita, ela representa um desafio mais difícil a ser superado.

No desenvolvimento da presente pesquisa, análises preliminares das práticas discursivas de participantes da MC do Rio de Janeiro apontam que, em suas reuniões, os participantes reproduzem relações assimétricas. Os líderes podem ser temporários, operando em uma base rotativa, mas aparenta ser uma forma de liderança especificamente masculina, exibindo características associadas com esse gênero, como força e assertividade. Assim, o movimento estudado tem uma tendência a excluir quem não age de tal forma e exige daqueles que desejam ou queiram ter voz, que ajam dessa forma. De acordo com Fraser (1997, p.78), as formas de controlar podem ser sutis. Soma-se a isso que os grupos subordinados não encontram voz ou as palavras "certas" para expressar suas ideias. Essa realidade representa a consequência de uma sociedade estratificada na qual diferentes grupos sociais desenvolvem estilos culturais com valores diferenciados. 
Dessa forma, conforme já mencionado, contribuições de grupos subordinados podem ser, simplesmente, não dadas a mesma atenção ou peso (IBID, p.79).

Quando aceitamos que o poder não é distribuído igualmente nos movimentos sociais, assim como na sociedade, podemos começar a reconstruir esses espaços em outras bases. Para tal, precisamos perceber que o processo de produção é tão importante quanto as coisas que produzimos. Ao invés de fingir que independência das construções socais da nossa sociedade é possível, ou aceitar visões utópicas como a horizontalidade como dadas, é necessário focar na construção de um espaço mais igualitário. Apenas ao entender isso como um processo constante, carente de monitoramento, talvez possamos nos engajar em práticas transformacionais.

Isso implica tornar visível as formas pelas quais as desigualdades permeiam os movimentos sociais e suas interações (IBID, p.80), além de abrir um diálogo sobre isso. Assim, podemos pensar em formas para combater as desigualdades ao invés de reproduzilas, tomando uma postura crítica em relação às nossas próprias práticas para entender suas relações com a cultura dominante, bem como a contribuição para a perpetuação da homogeneidade dos movimentos que participamos. Grupos de pedal exclusivamente femininos podem auxiliar a criação de solidariedade entre as mulheres, fomentando o empoderamento.

Arranjos como esses podem melhor promover a participação de grupos subordinados do que a insistência em um único grupo em que as desigualdades podem ser agravadas - em um espaço único, os grupos minoritários não teriam espaço para deliberar suas necessidades, seus objetivos e suas estratégias, ou para outros processos comunicativos sem a supervisão dos grupos dominantes Fraser (1997). Nesse sentido, teriam mais dificuldade para articular seus pensamentos, bem como para expor a falsa representatividade do grupo dominante. Grupo este, que, muitas vezes, representa apenas seus próprios interesses, rotulando as reivindicações dos grupos subordinados como assuntos que estão além do âmbito do grupo, ou de natureza privada (IBID, p.81). Por isso, ao formar seus próprios grupos, os grupos subordinados encontram vantagens, pois nesses espaços podem circular contra discursos, possibilitando a formulação de interpretações alternativas. 


\section{Considerações finais}

Da mesma maneira que um movimento como a MC auxilia no compartilhamento e na interpretação das agressões sofridas pelo ciclista devido à escolha do modal, a formação de grupos exclusivamente de mulheres pode contribuir para o compartilhamento e (re)interpretação das micro agressões sustentadas nesses mesmos movimentos. A valorização, pelos participantes do movimento, de uma performance convencionalmente masculina, acaba por implicitamente excluir as mulheres do espaço, da mesma forma que alguns motoristas procuram excluir os demais usuários do espaço público. Embora as mulheres possam performar traços "masculinos", tal performance foge das expectativas sociais reguladoras da interação, implicando em um custo social e dificultando sua participação da interação como parceiro de igual valor. Espaços dedicados às mulheres, sem a supervisão do grupo dominante, como rodas de conversa e grupos de pedal, facilitam novos processos de comunicação e a produção de novos significados. A partir de suas vivências nesses ambientes e a circulação de novas interpretações, é possível que as mulheres participem dos espaços mistos com olhares mais críticos, determinadas a desconstruir os displays de gênero esperados delas e reivindicar seu espaço, tanto na rua enquanto pedalam, quanto nos próprios movimentos que visam uma reorganização desse espaço.

Por esta razão, é imprescindível resistir às críticas direcionadas àqueles que lutam contra as agressões micro, pois são essas discriminações que normalizam o tratamento de determinados grupos como inferiores, criando abertura para violências em uma escala maior. Nas interações observadas no contexto do cicloativismo do Rio de Janeiro, a manutenção do status da masculinidade hegemônica torna-se visível pela falta de abertura para narradores diversos na construção dos grupos e de suas ações. Tais práticas reforçam relações assimétricas entre os participantes, perpetuando a homogeneidade dos grupos. No mais, no contexto de movimentos sociais que desejam romper com as estruturas de poder, a exclusão latente de grupos subordinados, pela manutenção de suas vozes na periferia, cria um cenário tão complexo quanto inquietante-um movimento que nunca cresce pela incorporação de pessoas marginalizadas ou menos privilegiadas, nunca conseguirá desafiar as hierarquias e injustiças existentes (CAMARENA, 2012).

\section{Referências bibliográficas}


BLICKSTEIN, S. \& HANSON, S. Critical Mass: forging a politics of sustainable mobility in the information age. Transportation, v. 28, p.347-362, 2001.

BRUZZONE, M. Putting the "Critical" in Critical Mass: Patriarchy, Radical Feminism and Radical Inclusiveness. In: CARLSSON, C.; ELLIOTT, L.; CAMARENA, C. Shift Happens! Critical Mass at 20. São Francisco: Full Enjoyment Books, 2012. p.131-141.

CARLSSON, C. The hidden class politics of bicycling, trains, cars, BART(!). In: Carlsson, C., Swanson, J. \& Andrade, H.D. (Eds.), Critical Mass Essays, Flyers, Images from San Francisco, 1992-1998. Disponível em: < http://www.scorcher.org/cmhistory $>$. Acesso em: jan. 2017.

CASTELLS, M. O Poder da Identidade. São Paulo: Paz e Terra. 1999.

CONTROL, S. Acabem com Todos os Carros. In: LUDD, N. Apocalipse Motorizado. São Paulo: Conrad, 2005. p.103-118.

DA MATTA, R. A Casa \& A Rua - Espaço, Cidadania, Mulher e Morte no Brasil. Rio de Janeiro: Rocco, 2000.

DAMIANI, A. L. Espaço e Geografia: Observações de Método - Elementos da obra de Henri Lefebvre e a Geografia; Ensaio sobre Geografia Urbana a partir da Metrópole de São Paulo. Tese de livre docência. Universidade de São Paulo, São Paulo, 2008.

FRASER, N. Rethinking the public sphere. In: Justice Interrupts - Critical reflections on the "post socialist" condition. New York: Routledge, 1997. p.69-98.

FURNESS, Z. Critical Mass, Urban Space and Velomobility, Mobilities, v. 2, n. 2, p. 299319, 2007.

GASTALDO, E. Goffman e as relações de poder na vida cotidiana. Revista brasileira de ciências sociais. São Paulo; v. 23, n. 68, p.149-53. Out. 2008.

GOFFMAN, E. A Representação do eu na vida cotidiana. Petrópolis: Vozes, 1975.

Behaviour in Public Places: Notes on the Social Organisation of Gatherings. New York: Free Press, 1963.

Gender Advertisements. New York: Harper \& Row, 1979.

The Arrangement Between the Sexes. In: Theory and Society, 4, p301-

$332,1997$.

GORZ, A. A Ideologia Social do Automóvel. In: LUDD, N. Apocalipse Motorizado. São Paulo: Conrad, 2005. p.73-82.

GRANIER, C. Abaixa o Carro. Viva a Bicicleta! In: LUDD, N. Apocalipse Motorizado. São Paulo: Conrad, 2005. p.119-122.

GUIMARÃES, A. C. Sociologia do trânsito. Relatório PIBIC. Pontifícia Universidade Católica do Rio de Janeiro, Rio de Janeiro, 2008.

JENKINS, R. The 21st-Century Interaction Order. In: Jacobsen, M.H. The Contemporary Goffman. New York: Routledge, 2010. p.257-74.

LEFEBVRE, H. The production of space. Oxford and Cambridge: Blackwell, 1991.

LOPES, G. Embaralhando as pernas: diferentes visões sobre a bicicleta como forma de mobilidade urbana. Dissertação (Mestrado em Geografia). Pontifícia Universidade Católica do Rio de Janeiro, Rio de Janeiro, 2010.

LUDD, N. Nós somos o trânsito! Ou Everyday is a Holiday. In: LUDD, N. Apocalipse 
Motorizado. São Paulo: Conrad, 2005. p.123-6.

MAGALHÃES, I. A análise de discurso crítica e a construção semiótica das identidades de gênero. DELTA. São Paulo; v. 21, p.179-205, 2005. Edição especial.

SMITH, G. Reconsidering Gender Advertisements: performativity, framing and display. In: Jacobsen, M.H. The Contemporary Goffman. New York: Routledge, 2010. p.16584.

Data de Recebimento: 05/05/2017

Data de Aprovação: 21/08/2017 


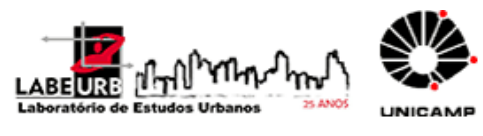

\section{Para citar essa obra:}

ORTON, Naomi Elizabeth. (Des)igualdade de gênero e a (i)mobilidade urbana contemporânea: uma visão goffmaniana In: RUA [online]. $\mathrm{n}^{\circ} .23$. Volume 2, p. 243 - 266 - e-ISSN 2179-9911 Novembro/2017. Consultada no Portal Labeurb - Revista do Laboratório de Estudos Urbanos do Núcleo de Desenvolvimento da Criatividade.

http://www.labeurb.unicamp.br/rua/

Capa: Disponível em <https://i.ytimg.com/vi/E0giQjm5vt4/maxresdefault.jpg>

\section{Laboratório de Estudos Urbanos - LABEURB}

Núcleo de Desenvolvimento da Criatividade - NUDECRI

Universidade Estadual de Campinas - UNICAMP

http://www.labeurb.unicamp.br/

\section{Endereço:}

LABEURB - LABORATÓRIO DE ESTUDOS URBANOS

UNICAMP/COCEN / NUDECRI

CAIXA POSTAL 6166

Campinas/SP - Brasil

CEP 13083-892

Fone/ Fax: (19) 3521-7900

Contato: http://www.labeurb.unicamp.br/contato 